\title{
Neurological Disturbances and Time Travel
}

\author{
Denielle Elliott \\ York University \\ dae@yorku.ca
}

\begin{abstract}
This paper, positioned at the intersection of anthropology, science and technology studies, and feminist affect theory, considers shifts in memory and neurological disturbances that accompany traumatic brain injuries. Anomia, or anomic aphasia, is the inability to recall certain words, names, or colors caused by damage to the parietal or temporal lobes in the brain. Anomia is a disorder 'on the verge' - there but not quite, a forgotten memory, reluctant to be conjured. How might experimental ethnographic memoir help us uncover such forgotten memories and make sense of neurological disturbances pathologized by science and medicine? My account contributes to a growing body of literature that uses ethnographic memoir as political critique, blending the personal and theoretical, situating the intimate within larger historical and social contexts. It suggests that ethnographic memoir, with attention to the affective interiority of memories, merged with theoretical analyses and political critiques of medicine and/or therapeutic interventions, offer new understandings of being and temporality.
\end{abstract}

\section{Neurological Disturbances}

We must not allow the fear of forgetting to overwhelm us. And then perhaps it is time to remember the future, rather than only worry about the future of memory.

—Andreas Huyssen, "Present Pasts: Media, Politics, Amnesia" 
My mom, talking about a summer past when we had been in Kamloops, prods me, "Don't you remember? You were eleven. There was that wild horse..." She continues, trying to fill in all the details, hoping she will trigger my memory with cues, that the images, sounds, smells, feelings from that summer will fall into place and that I will be able to share in this memory with her as she, now a senior who spends more time in the before, makes these temporal journeys into the past. There are many occasions like this. I try hard to remember. Sometimes her strategies work, and with each sensorial detail, the memory comes back into focus. At other times, I am at a loss and nothing emerges in my imagination. It is so clearly a memory that I do not share that I wonder if she remembers it correctly. Maybe I wasn't even there. Maybe she has dreamt it. She gets annoyed with me sometimes when I tell her I cannot remember. "Honestly, how can you not remember that?" she will say hastily, frustrated. Of course, she knows why I do not remember. I live with the permanent effects of a brain injury that left my frontal lobe reconfigured.

January 2008, Letter (excerpt) from Neurologist, Vancouver, BC

ASSESSMENT: Right frontal head injury, depressed skull fracture with epidural hematoma, and right frontal contusion. Concussive symptoms with minimal evident cognitive impairment. She's actually made a rather remarkable recovery.

I did have a rather miraculous recovery. A combination of pure luck, hardheadedness (in more than one sense), and skilled neurosurgeons who alleviated the pressure on my brain and rebuilt my skull. And yet, I live with a range of neurological "disturbances," sensorial sensations, and memory slippages. My memory loss seems to bother my mom, and others. A friend working in an allied "psy" field says to me in the sort of hushed tone once reserved for talking about things like cancer in the 1950s, "I hate to tell you this but people with acquired traumatic brain injuries are more likely to suffer from early onset dementia." Afterwards, I somewhat compulsively search Medline for papers on "increased incidence of dementia due to brain injuries" to find there are differing opinions. I ask my neurologist who immediately dismisses the psy fields as "quackery" and tells me that she thinks I might be protected from dementia due to the resiliency (i.e., "plasticity") of my brain matter. ${ }^{1}$ Whether it is true or not though is beside the point. I am left wondering why we are so bothered by forgetfulness, by memories mis/dis-placed?

This article is part memoir, part ethnography, part social study of medicine. ${ }^{2}$ As an experiment in ethnographic memoir, the autobiographical story I am going to tell 
should not be understood as straightforwardly biographical, nor perhaps even real since, according to neuroscientist Anil Seth (2016), the experience of self is a "controlled hallucination generated by the brain." The neuro fields, and some of the allied psy fields (i.e., psychology, psychiatry, neuropsychology), have a narrow understanding of brain injuries, one that does not resonate with my own. My understanding: the perspective of a social scientist, a critical ethnographer, a feminist scholar wanting to unsettle, disrupt, question neuroscientific ways of knowing and the academy more generally. But my understanding is deeper than that, not just analytical, nor "arm-chair." I write as someone who lives with an injured mind, the permanent, mostly invisible, afterlife of a traumatic brain injury. This semi-fictionalized, autobiographical experiment considers the texture of temporality, reflecting on how we know what is real, unreal, a hallucination, a memory, a confabulation (Luhrmann \& Fortier, 2017, p. 25; also see Pandian, 2012). As a critical ethnographer who studies medicine and science, I feel uniquely positioned to explore the fracture between these two different worlds of knowing and being, the embodied felt experience and the scientific gaze distorted through digital scans and standardized clinical measures. ${ }^{3}$ My field notes, medical data (including clinical records, CT and MRI imaging, surgery notes and summaries), and records of correspondence from the injury and care with medical professionals inform this memoir account. Specifically, I focus on memory "disturbances" that often accompany brain injuries. Acquired brain injuries, whether traumatic or milder concussions, may result in what the neurosciences typically define as memory impairments, deficits, or disorders. Yet these transformations in memory are diverse, and neurologists are challenged to find explanations to understand such disparate symptoms reported by patients. From retrograde amnesia to déjà vu experiences, like an old vinyl record player our memories skip, repeat, and sometimes get stuck in one place. 


\section{A Sense of Self}

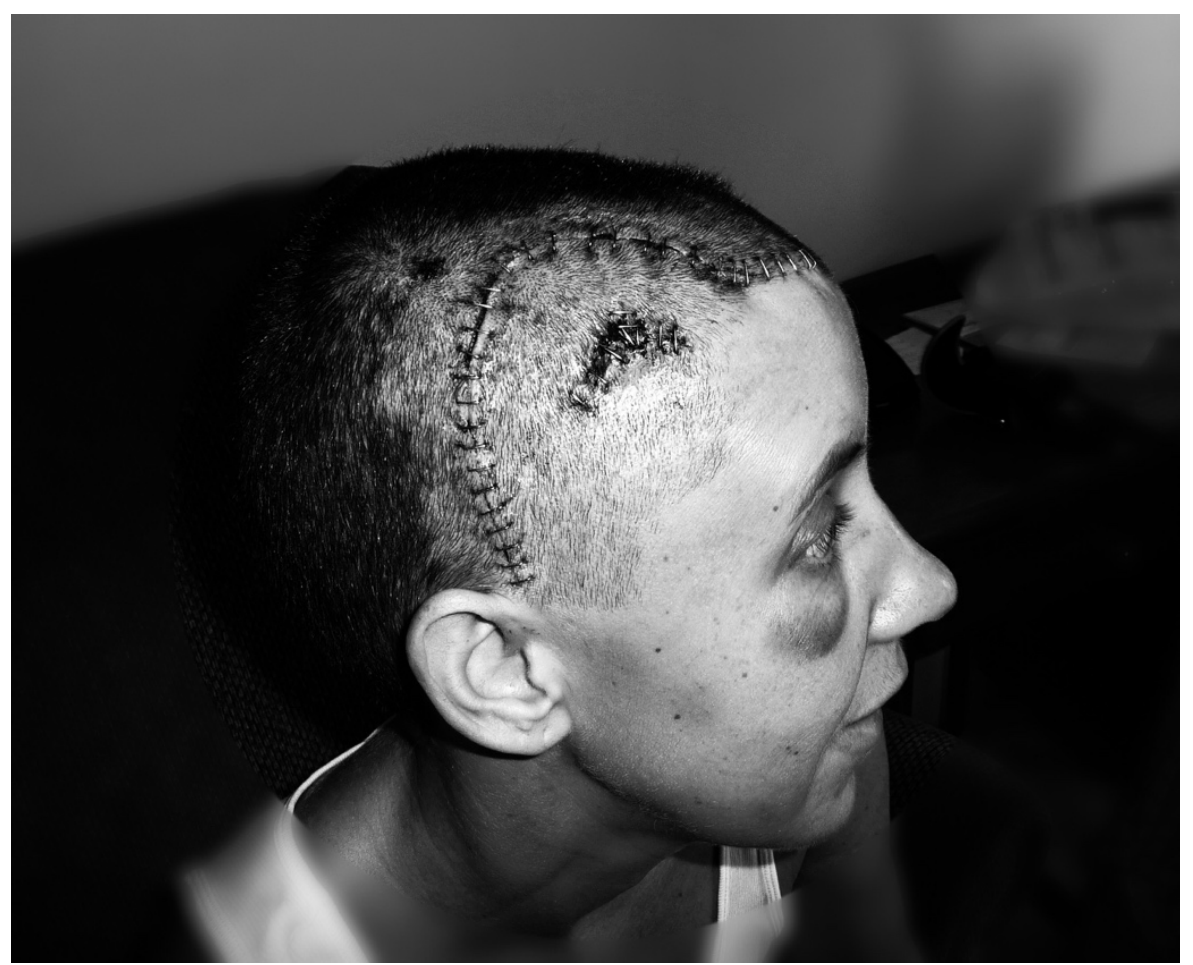

Figure 1. Released from the hospital, March 2009. Credit: Aldo Bonato. (Photograph still of author with staples after surgery.)

I am constantly reminded of my injury, of the event, by migraines, fatigue, tender scalp, memory disturbances, and a range of sensorial sensitivities to touch, smell, noise, and light (reminding me that this is not a purely intellectual exercise). Thus, any attempt to know brain injuries or memory changes, without attention to the sensorial, are seriously incomplete. Informed by the work of Lauren Berlant (2008; 2011; 2014), specifically her "sensing of history" and her attention to "affective intensities," I suggest this methodological experiment as a way to get at the inner transformations resulting from memory changes, what I experience as a state of "being otherwise" (Pandian \& McLean, 2017, p. 19). In her recent work, Sara Ahmed (2017) has suggested that we think of remembering events as a type of sensory act, and this reminds us to think about the complex relations between our senses, memories, and time (also see Berbeek \& Van Campen, 2015). If we ascribe to affect theory in an approach to memory loss and brain injuries, we must consider the sensorial for the physiological, symbolic, and mnemonic affects. I write this in that tradition but in a spirit of playfulness and creativity. (I am a time traveler.) An ethnographic memoir that accounts for the multi-sensorial of neurological disturbances and is attentive to the ephemerality of time and memories might offer more accurate or at least complicated accounts of being 
after traumatic brain injuries. I suggest that memory disturbances like anomia and déjà vu need novel ethnographic methods of investigation that can account for their evanescence and the way in which time ricochets through memory (Pandian \& McLean, 2017).

Such a project demands attention to the complex interiority of the mind and memory, forcing us to consider the imperceptible shifts in the act of remembering that are largely missed or glossed over in conventional scientific accounts of brain injuries and memory disruptions. My aim is to refine and enhance ethnographic memoir-attentive to multiple senses of knowing, and at once experimental, interventionist, performative, and speculative (Ingersoll, 2016). ${ }^{4}$ This approach moves away from traditional fieldwork practices to a way of knowing and remembering non-discursively (Massumi, 1995), a way to capture the hidden life of mind and memory. I suggest that this type of ethnographic memoir creates spaces of creativity, allows for travels in time and memory, and for the wondrous and frightening hallucinatory imagination to emerge. I imagine it as a way to investigate and convey that which feels indescribable, the "radical shifts in inner expression and aesthetic perception" (Irving, 2017, p. 26). Such opening up to the sorts of things we usually delete, or ignore, or don't have access to in our research, permits us insight into human consciousness, the imagination, and other ways of being, like those marked by changes in mind and memory. ${ }^{6}$ If cultivated, a multisensorial ethnographic memoir permits us to see and theorize that which lies beyond what we can only see in participant observation or hear in interviews; it gives us access to "muted registers of being and becoming" of the self (Myers, 2017, p. xii), including inventories of "intensity," as states of suspension and disruption (Massumi, 1995).

\section{Multiple Temporalities}

I understand memories not as cultural artifacts or isolated objects of possession, but as temporal practice that we can trace through experiences in the past, present, and future, preoccupied all along by the forgotten (Dib, 2012). ${ }^{7}$ Lina Dib elaborates on what it means to treat memory as practice or as an experience rather than as a thing we hold:

A memory enacted is then seen no longer as a discreet whole but rather as constantly shifting in its boundaries. Once more, as with Proust's madeleine, memory is synesthetic, involving an intertwining of visual, aural, haptic, and even olfactory senses in measurement and treatment. $(2012$, p. 67) 
Memory is also, as Andreas Huyssen (2000) argues, "always transitory, notoriously unreliable, and haunted by forgetting-in short, human and social" ( $p$. 38). Conceptualizing memories in these ways allows for more freedom in thinking about the ever-shifting and retreating nature of biological memories.8 Following, I imagine that if we reframe memory disturbances such as anomia and déjà vu as of another temporal dimension, and we approach them sensitive to the fleeting, sensorial, and affective, we might understand such changes not as pathologies or disorders, but as a rupture in temporality, another way of moving through time.9 Time travel. A multiplicity of temporalities emerge with traumatic brain injuries and with memory changes more generally.

Forgetfulness, forgetting, and the forgetful are subjects of the popular imagination as seen in movies such as Memento (Nolan, Todd, \& Todd, 2000), the film noir whose main character is unable to form new memories (suffering from anterograde amnesia) and tattoos reminders all over his body as he tries to solve the murder of his wife and the attack that left him with amnesia. In Still Alice (Glatzer \& Westmoreland, 2014) the audience watches as a professor copes with early onset dementia as she begins to forget all the details in her life. She is portrayed as tormented by the loss of memories, which compels her to write a reminder to her future self that she should eventually take her own life because she doesn't want to live without memories of herself and her family. In Eternal Sunshine of the Spotless Mind (Gondry, 2004) the future offers biotechnological innovations that allow us to wipe our disturbing memories clean, to start fresh without remembering painful pasts and traumatic events (also see Vassanji, 2016). ${ }^{10}$ In all three, the act of forgetting (even when chosen in the case of the last film) is portrayed as something to mourn, a loss too great to bear. Similarly, neurologists and allied psy fields generally understand changes in how we remember or what we remember as loss, a deficit, a pathology, an impairment.

These are states demanding intervention as treatment or cure, whether it is pharmaceutical (medicines, vitamins, or nutritional supplements that help us remember), psychological (hypnosis, eye movement desensitization and reprocessing, or cognitive behavioural therapy), or biotechnological innovations (biofeedback, use of digital devices). Michael Kahana, a neuroscientist at the University of Pennsylvania, suggests that the future includes surgically implanting a small device into "the cranium or chest" with "electrodes penetrating into the brain" that decode and stimulate the brain's centers responsible for memory. In explaining why such a device is necessary, Kahana said, "Losing one's ability to function in terms of cognition is one of the scariest things imaginable" (CBC Radio One, 2018, emphasis added). Such fear of forgetting or being forgetful has driven 
a multimillion-dollar industry of "brain games" such as Luminosity, Peak, or Elevate, in spite of contradictory evidence about whether they actually improve memory (Boot \& Kramer, 2014; Owen et al., 2010). ${ }^{11}$

This fear also feeds a new industry of digital technoscientific projects that aim to capture and record our memories. For instance, Mayer-Schönberger (2009) warns us that new digital medias such as Memories for Life are working towards a social world where we are unable to forget. "E-memories," those digitally recorded, mean that memories now live on forever, even after the death of the rememberer (Dib, 2012, p. 52). Focusing on Gordon Bell's digital memory project (MyLifeBits software), Dib highlights how e-memories are marketed as superior from "biological memories" as more reliable, factual, and unalterable. ${ }^{12}$ And, like the recent new television series on $\mathrm{HBO}$, Altered Carbon, e-memories are not stored in the brain but on a technological device, a "cortical stack" (Kalogridis \& Lenic, 2018) that transcends time, offering a "virtual immortality" (Dib, 2012, p. 60) through digital memories. In the future, memories are downloaded, stored, and eternal. As someone who is forgetful with a range of memory disturbances and as a researcher interested in memory, I find it curious how concerned people and popular culture generally are with memory loss or change.

As others have pointed out, our obsession with forgetfulness is with a particular type of memory-individual, embodied. At other times, we embrace and encourage amnesia. ${ }^{13}$ Colonialism prefers you forget, and thus an anti-colonial critique similarly demands remembering (Liebert, 2017; Rothberg, 2013). ${ }^{14}$ Colonialism haunts stories and histories of neurology and the brain sciences. Remember the role of anthropologists collecting skulls for museum displays (Roque, 2010), studying brain matter for disease (Anderson, 2008), or their role in the development of anthropometric practices (Anderson, 2003)? Measuring skulls, probing brain physiology, and the development of racial classifications based on those measurements are a part of the colonial history of the discipline we try to disassociate from, the sorts of things we wish we could forget. Does the future include an anti-colonial neurology (Savares, 2010)? Or, in other words, how does one reconcile a critical disability studies approach (which argues forgetfulness should not be pathologized, nor remembering valorised) with an anti-colonial approach that demands we collectively remember these violent, colonial pasts? Just because we want to remember, or need to remember, doesn't necessarily mean we have to pathologize forgetfulness. Though beyond the scope of this paper, these questions nevertheless are my travel companions in time. 


\section{Being}

THE KENYA POLICE

\section{MEDICAL EXAMINATION REPORT}

Date: February 2009 From: DCS Kisumu Police Station

To the: Aga Khan Hospital

Name: Dr. Denielle Elliott

Address: University of British Columbia...

General physical examination: Sick looking with swollen scalp and face.

Details of site, situation, shape and depth of injuries sustained: Severe head injury with compound, depressed skull fracture of the right frontal parietal temporal region with extradural haematoma. Linear fracture at the right orbit. Blunt trauma to posterior upper neck with gross oedema.

What were the immediate clinical results of the injury sustained and the assessed degree: GRIEVIOUS HARM

At the core of this paper are questions about epistemologies of being, the way we experience slippages in time, before/now/after, resulting from brain injury. For the purpose of this paper, I want to focus primarily on a specific type of memory change associated with acquired brain injuries: anomia. Anomia, or anomic aphasia (one form of aphasia), is the inability to recall certain words, names, or colors caused by damage to the parietal or temporal lobes in the brain. I experience anomia on a regular basis, daily in fact. I also experience a number of other memory disturbances, all of which have developed since I ended up with an acquired traumatic brain injury. During postdoctoral fieldwork in East Africa in 2009 I sustained serious bodily and head trauma. My skull was fractured in multiple locations, I had facial compression fractures, massive bruising on my neck, ribs, arm, and legs. In spite of the severity of the head trauma, I did not lose consciousness. If I had, I would not have been able to telephone a friend for help and I would have been left there, in a remote rural village plot of East Africa, to bleed to death alone. My friend rushed me to a small local private hospital where a CT scan was done after I started to vomit (a reliable clinical indicator of brain injury).

It was timely that this small private hospital had recently acquired a "new" CT scanner, which in fact was an older, used model donated from Russia. The scan clearly indicated a number of hematomas that needed to be drained because of the pressure building within my skull. An orthopedic surgeon conducted a cranioplasty, a procedure involving the removal of bone fragments to allow my 
swollen brain to expand and pools of blood trapped between the skull and the dura mater to drain, while a locally stationed American doctor from the Centers for Disease Control and Prevention looked on. Using a small, specialized drill, a burr hole was created in the skull so that the brain could swell without too much pressure. Months later, colleagues hesitantly told me that the drill had fallen to the floor during my surgery, and since the hospital only had one, they had to stand there awkwardly in the operating theatre for fifteen minutes while the piece that had fallen was re-sterilized for use again. The following day in recovery, an American neurologist who was in the region working on an HIV-related neurology clinical trial, came in to offer an assessment (since there was no neurologist available in western Kenya). ${ }^{15}$ At that time, she noted that my cognitive function was declining and so a decision was made, in consultation with the Canadian Embassy in Nairobi, to send me for follow-up care to Johannesburg, South Africa. An air ambulance was arranged and I was flown out the following day with two nurses, a doctor, and a colleague who volunteered to travel with me. KisumuLusaka-Johannesburg. A few days later, after additional tests and another CT scan, another craniotomy was performed, along with a cranioplasty to rebuild the right side of my skull, which had fractured and splintered into shards. Since then, I have been negotiating the dissonance between my experience of the injury and the expectations and understandings of a range of medical professionals.

June 28, 2011 Letter (excerpt) from Neurologist, Vancouver, BC Investigations: She had an MRI scan performed which we reviewed together. This showed an area of encephalomalacia, and gliotic changes in the right prefrontal region. She had a craniotomy deficit but no other abnormalities were seen.

Status post traumatic brain injury: Again, I think Denielle is doing remarkably well.

I reported to my neurologist a few months after the injury that I was forgetting words but he gently assured me that I had not forgotten the words; they were there, just reluctant, and with time the condition would disappear or lessen. He named it-anomia-and I went home to investigate and wrote the word down, repeated it dozens and dozens of times so I would not forget my forgetful condition. I still experience anomia, on a daily basis, but far less often than when I was first injured. Since anomia is generally associated with the left hemisphere where language capabilities are reportedly localized, my neurologists dismiss my reports of what I perceived as an ongoing struggle with word retrieval. They explain that since the physical trauma and damage was largely to the right hemisphere of my brain, it is unlikely that I would continue to experience anomia. Their cognitive tests (like the Montreal Cognitive Assessment) suggest my 
memory is within "normal range." In a clinical assessment in February 2016, I scored 29/30 on the Montreal Cognitive Assessment. I lost one point because I could not remember which hand did what on a traditional clock. ${ }^{16}$ Such assessments are notoriously poor reflections of those with above-average education and memory loss. For instance, educated individuals with early dementia are often missed on such tests because they score within the normal range. In March 2009, just weeks after the two neurosurgeries, I also scored normal on the same test. The intake worker at the Brain Injury Support Centre where I had been referred told me she did not quite know how to deal with me since their measures indicated I did not have a brain injury, even though she could clearly see the long scar across my head on my recently shaven head, where fortyfour staples had only just been removed (see Figure 1). My experience of a brain injury was not typical according to their measures: I did not have post-traumatic stress disorder, I was not having seizures, and I was not having problems with language. But I felt dramatically changed and felt many, albeit subtle and invisible, affects from the injuries. Their measures did not account for these elusive, sensorial, invisible, and often ephemeral changes. I experience other changes since the brain injury that I feel are clearly related to the brain injury, but, similarly, when I have reported these to neurologists or health care professionals working in brain injury support, these symptoms are often dismissed as inconsequential or not related to the injury. Their logic is that the types of changes I am reporting are associated with other areas of my brain, areas that were not directly injured. ${ }^{17}$

Yet what I also know about my brain injury is that the blows to my head were so significant, so powerful, that imagers note in my medical records a $3.0 \mathrm{~mm}$ midline shift of my brain (observable in early CT scans) and displaced ventricles. A concussion, considered a "mild brain injury," results when the brain bounces around within the skull, resulting in metabolic and/or structural damage to brain tissue. The displaced ventricles visualized on my CT scan indicated how intensely swollen my brain was, raising concern that it would also affect my brain stem. For weeks after, I was left literally off-balance. It is difficult to make sense of diagnoses in such situations that focus solely on specific regions of the brain with direct trauma. While the actual fracture to my skull and the impact may have occurred on the right frontal and temporal lobes, the force of the blow to my head impacted other regions and the brain as a whole, yet there is no mention of anomia in any of my neurological clinical records. 


\section{Anomia}

\section{EEG LABORATORY}

Activation Procedures: Photic stimulation produces a symmetrical driving response. Hyperventilation is not performed in this record. Impression: This record is mildly abnormal. The changes present in this record are consistent with mild and nonspecific electroencephalographic changes.

Comments: This study is obtained with the patient awake, drowsy and asleep. This study is abnormal. This study is abnormal due to the presence of sharply contoured slowing present over the right frontal and right anterior temporal regions.

We know that memory is unreliable in the best of circumstances. My memory seems increasingly volatile, fractured, partial, sometimes even proving false. And thus, the very process of researching memories, a memoir of forgetfulness, opens up questions about the real and imagined, my own recollection of the events, as my memory undergoes constant revision. Michael Taussig (2011) declares, "I swear I saw this." I think I did, but I no longer remember what "this" was. Or I think I saw it, but turns out I didn't. Reluctant memories, lost memories, false memories-they demand novel ethnographic approaches that allow such shifting, impermanent thoughts and memories to still mean something, even as they represent me being otherwise. They are "real," at least as much anything else in my life is real, even when they are false, incomplete, or hidden memories.

Though I reported (and continue to report) my experiences of anomia and other memory changes to my neurologists, I do so for record and understanding, less than expecting "a cure" or solution to my forgetfulness. ${ }^{18}$ As an academic, anomia can be embarrassing. It strikes me when I am particularly worn out, or overtired at work. I suffer from emotional and intellectual exhaustion, "brain fatigue," more than most (or more than most who do not live with the permanent effects of brain injuries). And like everyone else, my ability to remember and recall is also shaped by age, overstimulation, an overreliance on technology, and other factors. These exacerbate the neuro conditions I live with as a result of the brain injury. I have adapted to the changes in my memory. This includes a reliance on lists, notes to self, electronic reminders, and calendars. In teaching, it means a lot of preparation, so I write out detailed lectures in full before class. I make a substantial effort to make up for the changes in my memory so that it does not affect my work, but this effort is exhausting and certainly not failproof. I forget, or-in the case of anomia-I fail to retrieve important material deep inside my brain matter all the time. 
But anomia offers a different way to understand memory disruptions that result from injuries. I realized, once I moved past the frustration and embarrassment, that anomia offered an interesting intellectual experience in the temporal. Lauren Berlant (2014) again shapes my thinking, but here it is drawing on her engagement with the ellipsis, which she has theorized as "infrastructures of relation." Building on Dib's definition of memory as practice and as a process, I am thinking about memories and anomia as similarly "infrastructures of relation." Thinking with ellipses / as elliptical offers a way to get at anomia, memory disturbances, and brain injuries in a more productive way, as a process not necessarily negative. Berlant (2014) has talked about her own thinking as elliptical: that is to say, it both tracks concepts and allows for unfinishedness, inducing itself to become misshapen in the hope that by the time you return to the point of departure, so many things will have come into contact that the contours of the concept and the forms associated with its movement will have changed.

Anomia, and other memory changes, are like an ellipsis in that it is in the process of emerging; both the ellipses and anomia are marked by an "affective expectation of the experience of watching something unfold" (Berlant, 2011, p. 6) as our brain matter continually reconfigures itself with age and injury.

Berlant (2014) clarifies her approach to the elliptical:

The thing about an ellipsis is that it has a set of contradictory meanings.

An ellipsis is a sentence that I don't end because...I don't know how to. An ellipsis is a sentence I don't end because...you know what I mean. An ellipsis is a figure of return that isn't symmetrical. Ellipses might be a figure of loss or plenitude: Sometimes it is more efficient to go dot dot dot. Sometimes it's also a way of signaling an elision. Sometimes the referent is beyond words.

The ellipsis allows us to refer to something that might be "beyond words." Anomia and other memory disturbances might be understood as the escape of words-slippery, mischievous-hiding in our memory, forcing us to end midsentence, mid-thought, or to find alternatives that are good enough replacements. These moments when the word is on the tip of our tongue are moments of both elision and emergence. It's also a moment of suspension-I find myself caught in time. This sense of emergence opens up new ways of thinking about memory loss, neurological disturbances, and distortions of time. Not simply incoherent, or incomplete narratives, but narratives in formation, productive, speculative...The word is coming. For Berlant, the ellipsis represents a sense of being where one is left with questions rather than answers. For me, memory disruptions work the same way. Too often my thoughts, and memories, end with 
more questions than answers.

I'm using anomia here as just one example where the neurological rendering of memory disruptions chafe up against the patient's experience (or specifically my experience as patient). In the first few months after my injury, I was very frustrated by what felt like to me a type of memory loss. I couldn't find the words that I needed. Anomia is a condition "on the verge"-there but not quite, a forgotten memory, reluctant to be conjured. Considered a "disorder of naming" and a "disorder of word retrieval" (Goodglass \& Wingfield, 1997, p. 8), anomia is particularly common among those who have left-hemisphere damage or lesions. Although it may feel as if one has forgotten the word, and thus assume that there is a loss of data from the memory, in fact the words are not lost from memory. The issue is in recall. One is unable to retrieve the information or word even though it exists in the memory, just there, on the tip of the tongue. It is not considered the same sort of difficulty experienced by those individuals with dementia, or Alzheimer's, due to an actual loss of semantic memory.

There are many kinds of aphasia; anomic aphasia is just one of the many memory impairments categorized under aphasia (Head, 1921). Nineteenth-century neurologists Paul Broca, Carl Wernicke, and Ludwig Lichtheim are attributed with outlining the classical understanding of aphasia (Eling, 2011). It is associated with three different lesion sites within the brain: the temporo-parietal junction, the anterior periventricular region of the frontal lobe, and the inferior temporal lobe. Circumlocutions are common among those with anomic aphasia-that is, describing the word to the listener without ever actually saying the word. In those moments, we find generic fillers ("thingy" is one I frequently rely on) or other nonspecific words that are good enough, or act as temporary replacements until we find the word we were searching for. I can often identify the first letter (it starts with $b . .$.$) , but still the word itself escapes me. Too often, that missing word$ comes to me hours later, maybe in the middle of the night as I toss and turn, its retrieval too late for any conversation or lecture that it was intended for.

The definition and diagnosis of anomia relies on localization theory. Localization theories have a long history in neurosciences starting in the seventeenth century, arising from phrenology (and indirectly related to studies of race and anatomy conducted by physical anthropologists) in the nineteenth century. Paul Broca, Franz Joseph Gall, Carl Wernicke, and John Hughlings Jackson, among many others, were all proponents of localization theory, though in very different ways. ${ }^{19}$ Susan Leigh Star (1985) explored the development of the phrenology brain map and the theory of localization of the late nineteenth century in the face of 
scientific uncertainty. Localization theory understood particular functions to be associated with specific zones of neural anatomy. ${ }^{20}$ For instance, Broca's area is associated with speech, and the frontal lobe associated with emotions. Recently, localization theories have been revised away from a strict localized/functional approach to a more "systems" approach (with an emphasis on multiple memory systems), emphasizing a distributed neural network (Uttal, 2002; Squire, 2004), yet localization theory continues to shape neurosciences and clinical neurology.

Localization theory has been questioned by those such as William Uttal, who suggests that the very logic behind localization theory relies on two assumptions, neither without epistemological challenges. He explains, the first problem is that we assume that the cognitive processes being explored (and localized on the brain map) are "defined in a sufficiently precise manner for them to be dealt with as separable and distinct modules" (Uttal, 2002, p. 222). Second, this approach to understanding the brain assumes brain functions "are actually localized (i.e., represented or encoded) by neuronal activity in circumscribed regions of the brain as opposed to being broadly distributed throughout the brain" (Uttal, 2002, p. 223). He is very critical of localization theories, suggesting that the attribution of modules and faculties to the mind has always been "arbitrary and idiosyncratic" (Uttal, 2002, p. 225), and that research design has been "self-fulfilling and selfsupporting" (Uttal, 2002, p. 223). Tremblay and Dick (2016) echo this sentiment, arguing that theories that localize speech and language skills in particular regions of the brain are outdated and do not reflect current neurobiological understandings. They explain, "our emerging understanding of brain function is of mutual interactions and common control mechanisms" (Tremblay \& Dick, 2016, p. 9). Uttal (2001) also emphasizes how new visual technologies of seeing may limit neurology's capacity to make sense of that which is invisible or cognitive abilities that are complexly interconnected.

Although neuroimages are now more and more complex (conventional x-rays replaced with $\mathrm{fMRI}$ and $\mathrm{CT}$ imaging, for instance), they simultaneously create blind spots in brain injury assessments. The focus on relatively new brain imaging technologies discounts forms of knowing that are non-word and non-image based. The new visual images produced by CT, PET, and MRI technologies are believed to be more accurate representations of reality, yet the visual process has become increasingly artificial (Borck, 2008). This technological visualization has intensified the trend in neurology to understand brain lesions and injuries as localized in specific parts of the brain, thus affecting certain functions (for instance, frontal lobe lesions/injuries are associated with personality changes), rarely accounting for the complex ways in which the mind, brain, and body work 
together, or the ways in which the brain is a sum of its parts. The contemporary focus on the localization of brain injuries and trauma and the visualization of evidence renders other kinds of evidence and experience as immaterial, or designates it as non-evidence. Neurologists are rigorously trained to understand brain injuries within these paradigms of knowing—visual and localized-yet experiences of brain trauma like my own suggest the importance of accounting for that which falls outside of the specific localized diagnostics for traumatic brain injuries and for a more systems-based or holistic, or felt (Million 2013), approach.

\section{Time Travel}

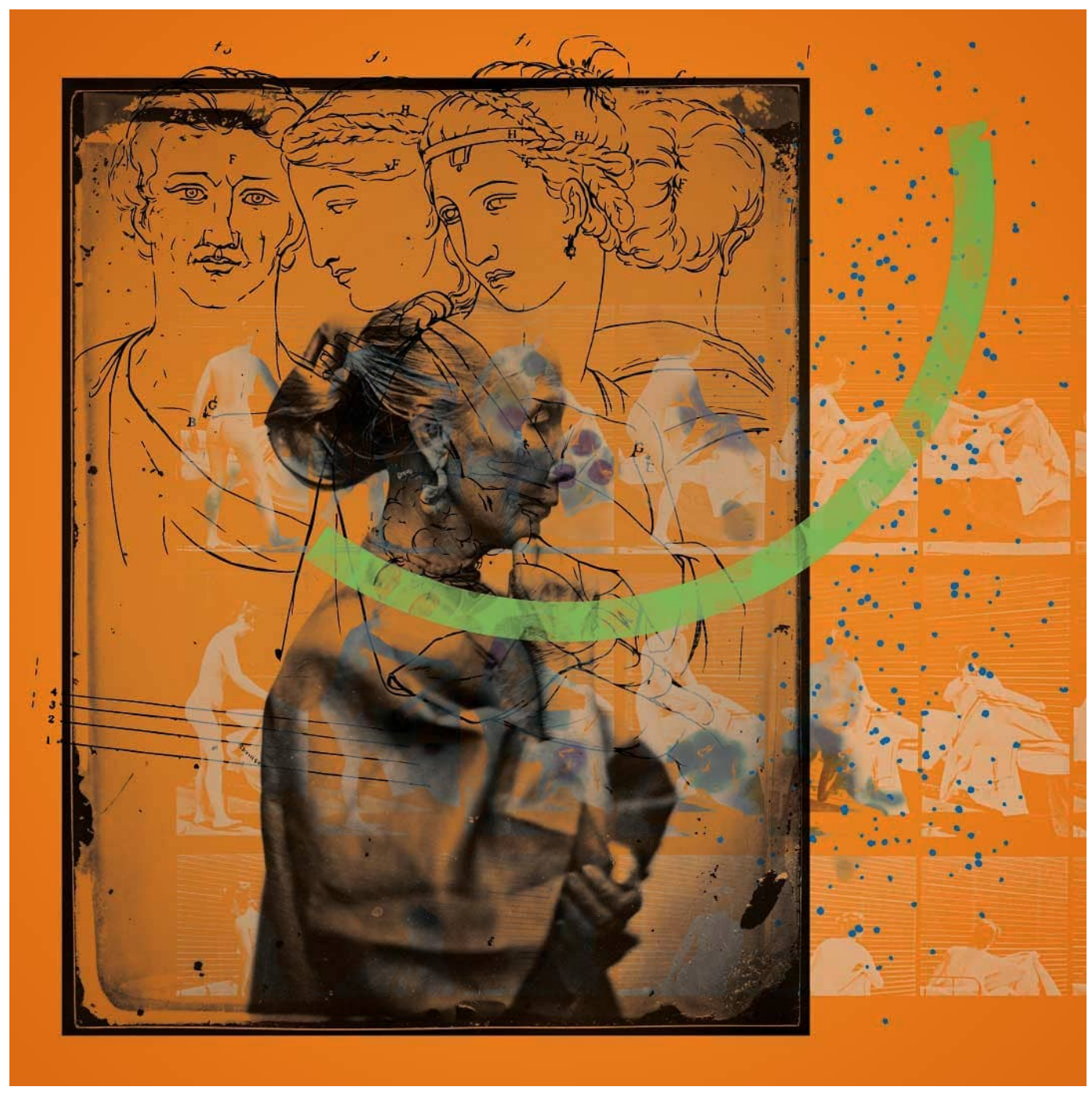

Figure 2. Auditory Hallucinations 2. Illustration credit: Leslee Lazar. [Montage illustration of auditory hallucinations by artist/neuroscientist Leslee Lazar.] 
Though certainly frustrating at times, even embarrassing, anomia offers possibilities. It is not a failed act of retrieval, but a slow movement through time, through a (stalled) process of retrieval where one is remembering and forgetting all at once. Ideas of temporality are critical to questions of memory as our sense of time-what is past, present, or future-blurs with these memory disturbances. As Elizabeth Grosz (2004) notes, temporality or time is one of the most obscure and elusive concepts for social theorists and physicists alike (see also Grosz, 2005; Rovelli, 2018). ${ }^{21}$ Temporality works then on parallel if not multiple levels in the acts of remembering, forgetting, and imagining through anomia. If we abandon the obsession with remembering the past, we can focus on questions of being and becoming, possibilities, and "time travel." I mean this both literally and conceptually-for anomia and other memory disruptions such as déjà vu disrupt conventional understandings of temporality. Anomia-without name-and déjà vu-caught in time-force us to rethink how we conceptualize memories, being, and temporality. Grosz (2004) suggests that we can only think of time "in passing moments, through ruptures, nicks, cuts, in instances of dislocation," but she also argues "it contains no moments or ruptures and has no being or presence, functioning only as continuous becoming" (p. 5). I want to argue differently, that we consider anomia and other memory disturbances as these very ruptures she denies. And to further suggest that a sensorial ethnographic memoir might allow us to understand these disruptions, this other temporal dimension, and the embodied (body and mind as one) experiences of being otherwise. If we take seriously phenomenological experiences of memory disturbances like anomia, as something more than a "disorder of naming," what might we learn about the textures of temporality experienced by the injured and noninjured?

Last night, I woke up surprised to find myself back in my own bedroom in Toronto. I was sure I had been at a friend's cottage, hundreds of miles away. It takes me a few minutes to place myself, to account for lost time. During moments like this, a few minutes seem like an eternity as I struggle to remember how I arrived at this place, when I arrived at this place. This happens with increasing frequency. Minutes, the odd day, lost or misplaced, slow to recover. In these moments, it feels as if I have literally been traveling through time, hurdled forward into the future, arriving discombobulated, out of place. Time lost. I lose time as I lose memory to forgetfulness. As Mahmoud Darwish (1995/2013) eloquently argues, memory is for forgetfulness. 


\section{Conclusion}

In his study of multiple personality disorder, lan Hacking (1995) writes, "I intend instead to find out why it is so taken for granted, by both sides, that memory is the key to the soul" (p. 20). If the memory is understood as the "key to the soul," to the self, and as defining our identity, what does it say about people like me whose memory is unreliable, filled with disjointed, disordered memories? ${ }^{22}$ For those of us with missing, displaced, or simply stubborn memories unwilling to be brought forth, are we no longer ourselves? Or is there another way to understand the transformations in our abilities to record, store, and recall the information of our lives?

Hacking's work reminds us that approaches to memories, how memories are formed, retained, recollected, are not shared between the sciences and the social sciences/humanities. If we consider this type of embodied knowledge from patients, with idiosyncratic experiences, that fall outside the typical clinical guidelines for neurology, if we make room for the subtle, invisible, quirky sensations reported, our understandings of brain injuries, the process of memory, and forgetfulness might be better understood. Perhaps the lived embodied, felt accounts of brain injury and memory disturbances can bridge the gaps between the social and scientific in understanding brain trauma and forgetfulness. In a very real way, such accounts make visible the processes of knowing (in the self and in scientific disciplines that study the self or mind). But more than that, attention to such embodied affective accounts of memory can shift how we understand memory changes from something inherently negative, a loss mourned, to simply another way of being and knowing the world, and perhaps, one's self.

Like others who have written about their own experiences with disabilities or neurodiversities, I do not assume that my experience of memory disruptions, loss, or the brain injury apply to anyone else (Wendell, 1993). But I do not generally miss the memories that have disappeared or been displaced, or those that stubbornly refuse to be retrieved. I do not feel lesser than, I do not feel like my identity has been lost. I know who I am without remembering a lost summer, or a name, a publication or place mid-lecture. The angst of forgetting (like that portrayed in the films I discussed earlier) is shaped by cultural and social ideals about memory and by corporate interests creating markets for tools, games, pharmaceuticals, and other biotechnologies.

The obsession with memories and remembering disparages against the forgetful. I suggest instead that we understand these conditions for their generative 
possibilities and productivity, something emerging, as simply another state of being; as a type of time travel that once you get used to it, and eschew the reductive neurological understandings of brain injuries, allows for embracing a state of being otherwise, one which is very grounded in the now and the future (Wilson, 2004). Am I a time traveler? Well, perhaps no, at least not in the sense of the 1980 s science fiction film Back to the Future or the British cult classic Doctor Who. But I certainly experience time and the world around me differently as a result of neural reconfigurations and the disruptions in my memory.

\section{Acknowledgements}

A Wenner-Gren Foundation for Anthropological Post-PhD award, for which I am grateful, funds this project. I am also thankful to Banu Subramaniam, editor at Catalyst, Joanne Muzak for her editorial craftsmanship, and two superb anonymous reviewers for their suggestions on this paper. I also owe special thanks to Cristina Moretti for providing important suggestions on questions of time and Leslee Lazar for his illustration. Alex Rewegan, Matthew-Wolf-Meyer, and Elsa Fan have all also contributed to this project in very different ways for which I greatly appreciate.

\section{Notes}

1See Tobias Rees's (2016) intriguing ethnography of Parisian neurobiologists and plasticity. Plasticity is also taken up in the edited collection by Bates and Bassiri (2016).

2 The paper aims to contribute to a growing body of literature like that of Anne Cvetkovich (2012) who writes about depression and the mental illness complex as someone who lives within that arrangement, as someone who experiences the mind/body betrayals and institutional logics that shape our experience of being ill or injured, in body or mind. Similarly, anthropologist Robert Murphy (2001) wrote about his own experience of being diagnosed with a tumour on his spinal cord and the subsequent transformation of his body as he made sense of becoming quadriplegic. These accounts approach changing bodies, institutional structures, epistemological logics, and popular imaginings through the critical analytics of the anthropological and the embodied first-person account. Also see these scholarly memoir accounts of illness: Berube (2016); Clare (2017); McLean (2007); Orr (2006); Stoller (2005); and Trivelli (2014).

${ }^{3}$ Memory loss as a cultural phenomenon has also garnered much attention in the sciences and social sciences, due to the aging baby boomer generation and the 
concern with dementia. Anthropologists Lawrence Cohen (1998; Leibing \& Cohen, 2006), Margaret Lock (2013), and Janelle Taylor (2008) have all written about memory loss, dementia research, and cultural understandings and institutional arrangements surrounding aging and "senility." Yet there is very little literature on the social study of forgetting (in the individual, biological sense, rather than the collective act of forgetting) outside of dementia or the aged. Also see Antze \& Lambek (1996).

${ }^{4}$ On methodological approaches in anthropology that demand attention to the sensorial, see Culhane (2017).

${ }^{5}$ Andrew Irving makes a compelling case for an "imperiled anthropology," which aims to explore and represent "the streams of inner dialogue and reverie" usually ignored by anthropology (2017, p. 74). He builds on the work of Vincent Crapazano (2004), who similarly has argued for a type of anthropological inquiry that takes seriously the imagination, reverie, and inner thoughts. Such work inspires my thinking on this project.

6 I see this paper also working to answer the question posted by Biehl and Locke (2017): "how can we ethnographically apprehend these worldly fabrications and the lives therein, constituted as they are by that which is unresolved?" (p. 10)

7 Dib's approach to memory is largely influenced by Karen Barad's (2003) work on "agential realism" and temporality. Current research in neurosciences place memories in the engram at the deeply neural and cellular level (Josselyn, Köhler, \& Frankland, 2017; Poo et al., 2016).

8 Furthermore, I want to suggest here that changes in memory from physical trauma, such as concussions or traumatic brain injuries, might be better understood as memory "disturbances" or "disruptions" in the productive sense, where disrupting narratives or disturbing conventional ways of knowing, produce alternative, sometimes more nuanced, accounts of neurodiversity.

9 Such changes might even be understood as "hopeful" in the Massumi (1995) sense of the affective. Matthew Wolf-Meyer's (n.d.) most recent manuscript, Unraveling, also critically examines the relationships between the self, the neurological disorder, and conceptions of the brain as the "basis of the self."

${ }^{10}$ In Nostalgia, the fictional novel by Vassanji (2016), individuals suffer from "leaked memory syndrome," a type of nostalgia where "reminders of discarded 
lives" leak into the conscious minds, requiring intervention from "nostalgia doctors." In this fictional future, past lives and the memories are replaced with artificial memories, as new personalities replace old ones, leaving traumatic pasts behind.

11 Boot and Kramer (2014) suggest that by 2020 the industry will be valued at more than US $\$ 6$ billion.

12 For more on Gordon Bell, see Total Recall (Bell \& Gemmell, 2009). On digital and/or e-memories and their affect on biological and cultural memories, see Van Dijck (2007).

13 For instance, on various forms of cultural amnesia encouraged or fostered by states, see Choudry (2010), Haaken (2002), and Luker (2005). We see cultural amnesia as dangerous, and counterproductive to anti-colonial or Indigenous movements, yet I do think that some people want to forget. This is related in some senses to the work of Dian Million (2013), who critiques trauma discourses as they are taken up by Indigenous groups in Canada and fields of psychology and then celebrated by the colonial Canadian state.

${ }^{14}$ I thank an anonymous reviewer for making this point.

15 I was in western Kenya working on an ethnography of a PrEP clinical trial for HIV that was being conducted by researchers at the University of Washington and University of California, San Francisco. The region at that time had one of the highest rates of HIV infection in Sub-Saharan Africa, and as a result there were multiple HIV/AIDS clinical trials being conducted by state and non-governmental organizations, largely from the United States.

16 I contested and argued that such a question was no longer fair given that we are largely surrounded by digital clocks and rarely see a traditional clock with a big hand and little hand. My neurologist responded by saying, "That's the point."

17 For instance, my experience with hiccups after the brain injury, which I have written about elsewhere; see Elliott (2016).

18 There are no cures, and rarely certainty about my ongoing symptoms. The "uncertainty" of neurosciences has been discussed by a number of scholars. See Fitzgerald (2017); Star (1985); and Wolf-Meyer (2018). 
${ }^{19}$ For more details on their contributions to localization theory and the neurosciences, see Lanczik \& Keil (1991) and Kaitaro (2001). On Franz Gall's influence and the three time periods of localization theory, see Zola-Morgan (1995).

20 For more detailed social studies of localization, see Abraham (2003, 2012); Borck (2008); Dumit (1999, 2004); Rose (2007); and Saunders (2008).

21 See the ethnographic accounts of time by Bear (2016); Davis (2017); Majumder (2017) in conversation with Zee; Peteet (2018); Pandian (2012); and Zee (2017).

22 See lan Hacking's Rewriting the Soul (1995) for his archeology of the memory sciences and the politicization of memories.

\section{References}

Abraham, T. (2003). Integrating mind and brain: Warren S. McCulloch, cerebral localization, and experimental epistemology. Endeavour, 27(1), 32-36.

Abraham, T. (2012). Transcending disciplines: Scientific styles in studies of the brain in mid-twentieth century America. Studies in History and Philosophy of Biological and Biomedical Sciences, 43(2), 552-568.

Ahmed, S. (2017). Living a feminist life. Durham, NC: Duke University Press.

Anderson, W. (2003). The cultivation of whiteness: Science, health, and racial destiny in Australia. New York, NY: Basic Books.

Anderson, W. (2008). The collectors of lost souls: Turning kuru scientists into whitemen. Baltimore, MD: Johns Hopkins University.

Antze, P., \& Lambek, M. (Eds.). (1996). Tense past: Cultural essays in trauma and memory. New York, NY: Routledge.

Barad, K. (2003). Posthumanist performativity: Toward an understanding of how matter comes to matter. Signs: Journal of Women in Culture and Society, 28(3), 801831.

Bates, D., \& Bassiri, N. (Eds.). (2016). Plasticity and pathology: On the formation of the neural subject. New York, NY: Fordham University Press.

Bear, L. (2016). Time as technique. Annual Review of Anthropology, 45, 487-502.

Bell, G., \& Gemmell, J. (2009). Total recall: How the e-memory revolution will change everything. Boston, MA: Dutton.

Berbeek, C., \& van Campen, C. (2015). Inhaling memories: Smell and taste memories 
in art, science and practice. Senses \& Society, 8(2), 133-148.

Berlant, L. (2008). Thinking about feeling historical. Emotion, Space and Society, 1(1), 4-9.

Berlant, L. (2011). Cruel Optimism. Durham, NC: Duke University Press.

Berlant, L. (2014, January 30). Interview with Andy Campbell. Art Forum. Retrieved from https://www.artforum.com/words/id=45109

Bérubé, M. (1996). Life as we know it: A father, a family, and an exceptional child. New York, NY: Pantheon.

Biehl, J., \& P. Locke (Eds.). (2017). Unfinished: The anthropology of becoming. Durham, NC: Duke University Press.

Boot, W. R., \& Kramer, A. F. (2014). The brain-games conundrum: Does cognitive training really sharpen the mind? Cerebrum (November-December).

Borck, C. (2008). Recording the brain at work: The visible, the readable, and the invisible in electroencephalography. Journal of the History of the Neurosciences, 17(3), 367-379.

CBC Radio One. (2018, February 19). Give your memory a workout: Scientists explore high-tech and low-key ways to improve recall [Radio program episode]. In I.

Colabrese \& S. Dufresne (Producers), The Current. Retrieved from https://www.cbc.ca/radio/thecurrent/the-current-for-february-19-2018-

1.4541777/give-your-memory-a-workout-scientists-explore-high-tech-and-lowkey-ways-to-improve-recall-1.4541799

Choudry, A. (2010). What's left? Canada's "global justice" movement and colonial amnesia. Race \& Class, 52(1), 97-102.

Clare, E. (2017). Brilliant imperfection: Grappling with care. Durham, NC: Duke University Press.

Cohen, L. (1998). No aging in India: Alzheimer's, the bad family, and other modern things. Berkeley, CA: University of California Press.

Crapanzano, V. (2004). Imaginative Horizons: An essay in literary-philosophical anthropology. Chicago, IL: University of Chicago Press.

Culhane, D. (2017). Sensing. In D. Elliott \& D. Culhane (Eds.), A different kind of ethnography: Imaginative practices and creative methodologies (pp. 45-68). Toronto: University of Toronto Press.

Cvetkovich, A. (2012). Depression: A public feeling. Durham, NC: Duke University Press.

Darwish, M. (2013). Memory for forgetfulness: August, Beirut, 1982. Berkeley, CA: 
University of California Press. (Original work published in 1995)

Davis, E. (2017). Time machines: The matter of the missing in Cyprus. In J. Biehl \& P. Locke (Eds.), Unfinished: The anthropology of becoming (pp. 217-242). Durham, NC:

Duke University Press.

Dib, L. (2012). The forgetting dis-ease: Making time matter. differences, 25(3), 42-73.

Dumit, J. (1999). Objective brains, prejudicial images. Science in Context, 12(1), 173201.

Dumit, J. (2004). Picturing personhood: Brains scans and biomedical america.

Princeton, NJ: Princeton University Press.

Eling, P. (2011). Lichtheim's golden shot. Cortex, 47, 501-508.

Elliott, D. (2016, November 17). An ethnography of invisibility: Neuro-medicine and felt theory. Paper presented at Affective Evidence session, at the American Anthropology Association Annual Conference, St. Paul, MI.

Fitzgerald, D. (2017). Tracing autism: Uncertainty, ambiguity, and the affective labor of neuroscience. Seattle, WA: University of Washington Press.

Glatzer, R., \& Westmoreland, W. (Directors). (2014). Still Alice [Motion picture]. United States: Sony Pictures.

Gondry, M. (Director) (2004). Eternal Sunshine of the Spotless Mind [Motion picture]. United States: Focus Features.

Goodglass, H., \& Wingfield, A. (Eds.). (1997). Anomia: Neuroanatomical and cognitive correlates. New York, NY: Academic Press.

Grosz, E. (2004). The nick of time: Politics, evolution, and the untimely. Crows Nest, AU: Allen \& Unwin.

Grosz, E. (2005). Time travels: Feminism, nature, power. Durham, NC: Duke University Press.

Haaken, J. (2002). Cultural amnesia: Memory, trauma, and war. Signs: Journal of Women in Culture and Society, 28(1), 455-457.

Hacking, I. (1995). Rewriting the soul: Multiple personality and the sciences of memory. Princeton, NJ: Princeton University Press.

Head, H. (1921). Aphasia: An historical review. Brain, 43(4), 390-411.

Huyssen, A. (2000). Present pasts: Media, politics, amnesia. Public Culture, 12(1), 2138.

Ingersoll, K. A. (2016). Waves of knowing: A seascape epistemology. Durham, NC: Duke University Press. 
Irving, A. (2017). The art of life and death: Radical aesthetics and ethnographic practice. London: HAU Books.

Josselyn, S. A., Köhler, S., \& Frankland, P. W. (2017). Heroes of the engram. Journal of Neuroscience, 37(18), 4647-4657.

Kaitaro, T. (2001). Biological and epistemological models of localization in the nineteenth century: From Gall to Charcot. Journal of the History of the Neurosciences: Basic and Clinical Perspectives, 10(3), 262-276.

Kalogridis, L., \& Lenic, J. (2018). Altered carbon [Television series]. United States: Phoenix Pictures.

Lanczik, M., \& Keil, G. (1991). Carl Wernicke's localization theory and its significance for the development of scientific psychiatry. History of Psychiatry, ii, 171-180.

Leibing, A. \& Cohen, L. (Eds.). (2006). Thinking about dementia: Culture, loss, and the anthropology of senility. New Brunswick, NJ: Rutgers University Press.

Liebert, R. J. (2017). Beside-the-mind: An unsettling, reparative reading of paranoia. Subjectivity, 10(1), 123-145.

Lock, M. (2013). The Alzheimer conundrum: Entanglements of dementia and aging. Princeton, NJ: Princeton University Press.

Luhrmann, T., \& Fortier, M. (2017). The anthropology of mind: Exploring unusual sensations and spiritual experiences across cultures. An interview with Tanya Luhrmann. ALIUS Bulletin, 1, 25-36.

Luker, T. (2005). "Postcolonising" amnesia in the discourse of reconciliation: The void in the law's response to the stolen generations. Australian Feminist Law Journal, 22(1), $67-88$.

Majumder, A. (2017, June 15). The times of sand: An Interview with Jerry C. Zee. Dialogues, Cultural Anthropology. Retrieved from https://culanth.org/fieldsights/1147the-times-of-sand-an-interview-with-jerry-c-zee

Massumi, B. (1995). The autonomy of affect. Cultural Critique, 31(Autumn), 83-109.

Mayer-Schönberger, V. (2009). Delete: The virtue of forgetting in the digital age. Princeton, NJ: Princeton University Press.

McLean, A. (2007). When the borders of research and personal life become blurred: Thorny issues in conducting dementia research. In A. McLean \& A. Leibing, The shadow side of fieldwork: Exploring the borders between ethnography and life (pp. 262287). Malden, MA: Blackwell Publishing.

Million, D. (2013). Therapeutic nations: Healing in the age of Indigenous human rights. Tucson, AZ: University of Arizona Press. 
Murphy, R. (2001). The body silent: The different world of the disabled. New York, NY: W.W. Norton.

Myers, N. (2017). Introduction. In G. Bakke \& M. Peterson (Eds.), Between matters and method: Encounters in anthropology and art (pp. xii-xii). London: Bloomsbury Press.

Nolan, C. (Director), Todd, J., \& Nolan, C. (Writers). (2000). Memento [Motion picture]. United States: Summit Entertainment.

Orr, J. (2006). Panic diaries: A genealogy of panic disorder. Durham, NC: Duke University Press.

Owen, A. M., Hampshire, A., Grahn, J. A., Stenton, R., Dajani, S., Burns, A. S.,...\& Ballard, C. G. (2010). Putting brain training to the test. Nature, 465(7299), 775-778.

Pandian, A. (2012). The time of anthropology: Notes from a field of contemporary experience. Cultural Anthropology, 27(4), 547-571.

Pandian, A., \& McLean, S. (2017). Introduction: Archipelagos, A voyage in writing. In A. Pandian \& S. McLean (Eds.), Crumpled paper boat: Experiments in ethnographic writing (pp. 11-28). Durham, NC: Duke University Press.

Peteet, J. (2018). Closure's Temporality: The cultural politics of time and waiting. The South Atlantic Quarterly, 117(1), 43-64.

Poo, M. M., Pignatelli, M., Ryan, T. J., Tonegawa, S., Bonhoeffer, T., Martin, K. C.,... \& Mullins, C. (2016). What is memory? The present state of the engram. BMC Biology, 14(1), art. no. 40.

Rees, T. (2016). Plastic reason: An anthropology of brain science in embryogenetic terms. Berkeley, CA: University of California Press.

Roque, R. (2010). Headhunting and colonialism: Anthropology and the circulation of human skulls in the Portuguese Empire, 1870-1930. New York, NY: Palgrave.

Rose, N. (2007). The politics of life itself: Biomedicine, power, and subjectivity in the twenty-first century. Princeton, NJ: Princeton University Press.

Rothberg, M. (2013). Remembering back: Cultural memory, colonial legacies, and postcolonial studies. In G. Huggan (Ed.), The Oxford handbook of postcolonial studies (pp. 359-379). Oxford: Oxford University Press.

Rovelli, C. (2018). The order of time. New York, NY: Riverhead Books.

Saunders, B. (2008). CT suite: The work of diagnosis in the age of noninvasive cutting. Durham, NC: Duke University Press.

Savares, R. J. (2010). Toward a postcolonial neurology: Autism, Tito Mukhopadhyay, and a new geo-poetics of the body. Journal of Literary and Cultural Disability Studies, 4(3), 273-290. 
Seth, A. (2016, November 2). Consciousness: The real problem. aeon. Retrieved from https://aeon.co/essays/the-hard-problem-of-consciousness-is-a-distractionfrom-the-real-one

Squire, L. (2004). Memory systems of the brain: A brief history and current perspective. Neurobiology of Learning and Memory, 82(3), 171-177.

Star, S. L. (1985). Scientific work and uncertainty. Social Studies of Science, 15(3), 391427.

Stoller, P. (2005). Stranger in the village of the sick: A memoir of cancer, sorcery, and healing. Boston, MA: Beacon.

Taussig, M. (2011). I swear I saw this: Drawings in fieldwork notebooks, namely my own. Chicago, IL: University of Chicago Press.

Taylor, J. S. (2008). On recognition, caring, and dementia. Medical Anthropology Quarterly, 22(4), 313-335.

Tremblay, P., \& Dick, A. S. (2016). Broca and Wernicke are dead, or moving past the classic model of language neurobiology. Brain and Language, 162, 60-71.

Trivelli, E. (2014). Depression, performativity and the conflicted body: An autoethnography of self-medication. Subjectivity, 7(2), 151-170.

Uttal, W. (2001). The new phrenology: The limits of localizing cognitive processes in the brain. Cambridge, MA: MIT Press.

Uttal, W. (2002). Précis of the new phrenology: The limits of localizing cognitive processes in the brain. Brain \& Mind, 3(2), 221-228.

Van Dijck, J. (2007). Mediated memories in the digital age. Palo Alto, CA: Stanford University Press.

Vassanji, M. G. (2016). Nostalgia: A novel. Toronto, ON: Doubleday Canada.

Wendell, S. (1993). Feminism, disability and transcendence of the body. Canadian Woman Studies, 13(4), 116-122.

Wilson, E. A. (2004). Psychosomatic: Feminism and the neurological body. Durham, NC: Duke University Press.

Wolf-Meyer, M. (N.d.) Unraveling: Remaking American personhood in a neurological age. [Unpublished manuscript].

Wolf-Meyer, M. (2018, February 6). What can we do with uncertainty? Somatosphere. Retrieved from http://somatosphere.net/forumpost/what-can-we-do-withuncertainty

Zee, Jerry C. (2017). Holding patterns: Sand and political time at China's desert 
shores. Cultural Anthropology, 32(2), 215-241.

Zola-Morgan, S. (1995). Localization of brain function: The legacy of Franz Joseph Gall (1758-1828). Annual Review of Neurosciences, 18, 359-383.

\section{Author Bio}

Denielle Elliott is a cultural anthropologist who teaches on postcolonial and indigenous science studies, the anthropology of biomedicine, and social suffering in the Departments of Social Science and Anthropology at York University in Toronto. She is co-founder and co-curator of the Centre for Imaginative Ethnography, coeditor of A Different kind of ethnography: Imaginative practices and creative methodologies (2016, University of Toronto Press), and the author of Reimagining science and statecraft in postcolonial Kenya: Stories from an African scientist (2018, Routledge). 